\title{
CONTROL OF STARTING MODES OF AN APRON CONVEYOR MULTI-MOTOR ELECTRIC DRIVE
}

\author{
Kelisbekov A.K. ${ }^{1 *}$, Daniyarov N.A. ${ }^{2}$, Akhmetbekova A.M. ${ }^{1}$, Orazbayev K.N. ${ }^{3}$ \\ ${ }^{1}$ O.A. Baikonurov Zhezkazgan University, Zhezkazgan, Kazakhstan, akelisbekov@mail.ru \\ ${ }^{2}$ Kazakhmys Corporation" LLP, Karaganda, Kazakhstan \\ 3I. Razzakov Kyrgyz State Technical University, Bishkek, Kyrgyzstan
}

\begin{abstract}
The practice of operating an apron conveyor at mining enterprises has shown that, due to their design features, they can be successfully applied in various industries for transporting a wide range of goods. Starting a multi-drive chain conveyor of large length is a rather difficult task, since this process can be accompanied by excessive relaxation of the traction body. Especially unfavorable are the conditions for starting an apron conveyor, the belt of which has sagging sections, as a result of which the rigidity of the working body, which is a function of its tension and load on it, is relatively small. In this regard, ensuring a smooth start of a multi-motor chain conveyor is an important practical task and is undoubtedly relevant for managing and maintaining a workable dynamic state of the main an apron conveyor structure operated in difficult mining and geological conditions.A method of controlling the starting mode of a multi-motor electric drive operation of an apron conveyor to ensure its smooth start and to reduce dynamic loads, to increase the service life of the traction belt and to reduce maintenance costs was developed.
\end{abstract}

Keywords: an apron conveyor, multi-motor electric drive, start-up mode control, smooth start-up.

\section{Introduction}

The operation of a conveyor is known to be characterized by a certain sequence of technological processes: start-up, motor, steady-state, emergency and braking modes. At the same time, ensuring a smooth start-up of a multi-motorapron conveyor is of great practical importance and is undoubtedly relevant for the control and maintenance of an efficient static and dynamic state of the main an apron conveyor structure operated in complicated mining and geological conditions [1-4].When operating long main apron conveyors, there are used multi-motor designs. With a reloading-free scheme of transporting the rock mass, due to the presence of a large number of intermediate drives inapron conveyor, it is necessary to solve the problems of controlling the starting modes of multi-motor electric drives operation and automatic distribution of the total load between its drives [5-7].

Purpose of work is development of a method to controlling the starting modes of the multi-motor electric drive of an apron conveyor operation by means of a frequency-controlled electric drive.

\section{Analyzing the problems and features of the starting mode of multi-drive an apron conveyor operation}

The studied experience of operating multi-drive chain conveyors shows that a high efficiency of their use is possible provided that conveyors are equipped with systems and tools of automatic distribution of the conveyor total load between its drives, regulating the speed of the conveyor belt, eliminating the equalizing forces in the traction circuit of the conveyor, and a number of other factors.

It is known that starting a long multi-drive an apron conveyor is a rather difficult task, since this process can be accompanied by excessive relaxation of the traction element. The conditions for starting an apron conveyor, which belt has sagging sections are especially unfavorable, and the working body rigidity that depends on its tension and the load on it, is relatively small.It is also known that in chain conveyors there are kinematic gaps between the individual links of the mechanism and slacks in the traction chains, etc. The presence of slacks, gaps, as well as the elastic properties of the traction-bearingbody causes significant mechanical stresses in the parts of the conveyor when starting electric drives. These overloads often reach high values with which one or another part of the conveyor fails [8]. The processes taking place in this case 
are very complex and oscillatory in nature. It should be noted that decreasing dynamic overloads in the drive elements and the traction-bearing body of the chain conveyor during start-up can be achieved in practice by reducing the reduced kinematic clearance of the mechanism and the initial starting torque of the electric drive. The initial value of the reduced kinematic clearance is determined by the manufacturing technology of the conveyor elements and increases with the service life due to wear. In this regard, the most effective way to reduce mechanical stresses is to lower artificially the initial motor torque to values that are lowerthan the resistance torque. This engine torque is called preliminary. When switched on with a preliminary torque, only the kinematic clearance and slack in the conveyor traction chain are taken up.

It is known that for unregulated asynchronous electric drives of mining machines including conveyors, starting modes are the most difficult. They are characterized by large starting currents that are many times higher than the nominal values and fluctuations in the starting torque [9 - 11]. This is, on the one hand, the cause of overheating the windings of the electric motor and decreasing its resource, and on the other hand, it leads to overloads in the gearboxes and in the chain traction unit. Large inrush currents also have a negative effect on electrical networks leading to unacceptable voltage drops [12 - 14].In connection with the abovesaid, in this work there are considered the existing technical solutions for starting multi-motor chain conveyors, their features are analyzed and their advantages and disadvantages are identified.

\section{Development a of controlling the multi-motorelectric drive of the anapron conveyor starting method}

For multi-drive conveyors, the solution to the start-up problem is very complicated, since in the presence of intermediate drives, control of the initial tension of the traction element is possible only when a tensioner is placed at each drive, which is constructively feasible but difficult.

There is a known method of tensioning the traction body of a multi-drive conveyor that is characterized by fixing the traction body at the tensioning station, turning on the drive of the tensioning station and sequential tensioning the sections of the traction body between the drives of the traction body by braking the initial part of each section and, then, moving the end part of this section with the following fixing.It differs in that in order to increase reliability of the traction body due to its optimal tension, the tension of the sections of the traction body between the drives is carried out by simultaneous turning on all the drives of the traction body and subsequent sequential braking the drives of the traction body, starting from the first drive of the traction body along the way of its movements [15].

It should be noted that the proposed method considers only preliminary tension of the traction element using an electric drive and a hydraulic tensioning station before starting the conveyor, without acceleration and reaching the nominal rotation speed of the conveyor electric drive. The performance of the take-up station when operating at low ambient temperatures deteriorates, which in general reduces reliability of the conveyor drive. There is also known a method of smooth starting a multi-motor electric drive of an apron conveyor that is based on measuring the load currents and isolating their active components, as well as in controlling the drives during the start-up process. At this in the process of starting the multi-motor electric drive of an apron conveyor, at the initial start-up moment, the minimum rotation frequency of the conveyor electric drives is set, and with intense increasing the active component of the master drive load current, the reference for the rotation speed of the master and slave drives is increased to the nominal value [16].

This article describes a method of smooth starting a two-drive apron conveyor without braking the tail driven electric drive, which does not fully ensure the working branch tension of the traction-bearing body of an apron conveyor.Based on the analysis and identification of the above solution shortcomings, there has been proposed a technical solution that can be used to control an interconnected four-motor electric drive when starting an apron conveyor.The task of the proposed method is to provide control of the interconnected multi-motor electric drive of an apron conveyor in starting modes, taking into account elastic properties of the traction-bearing body, and the technical result is to increase reliability of an apronconveyor operation by reducing the dynamic loads on the traction-bearing body in starting modes and increasing its resource.

The essence of the technical solution consists in the method of controlling a multi-motor electric drive of an apron conveyor in starting modes that is interconnected through an elastic traction element based on measuring load currents and isolating their active components. It differs in that, in the process of starting an interconnected multi-motor electric drive of an apron conveyor, the working branch of the traction element is pretensioned in each section by a corresponding electric drive, for which at the initial moment of start-up the last, fourth slave conveyor drive is slowed down. Then, in the following sequence, there is started the third 
intermediate electric drive, the second intermediate electric drive and then the first master electric drive. They, in their respective sections at the minimum speed movements extend the working branch of the traction-carrying body. When the branch tension in all the sections reaches the design value, as evidenced by increasing the consumed load current of the first, second and third electric drives, the corresponding electric motors synchronously, with the same acceleration, increase the rotation speed of all the drives to the nominal value [17].On the basis of this proposed method of controlling the starting mode of operation, a mathematical descriptionhas been developed that describes the dynamics of this technological mode of operation.

\section{Mathematical description of a four-drive an apron conveyor in the starting mode of operation}

The multi-drive apron conveyor is stared at the creeping speed until the moment of acceleration. The proposed scheme for starting a four-drive apron conveyor is shown in Figure 1. The fourth slave electric drive is in the decelerated state.

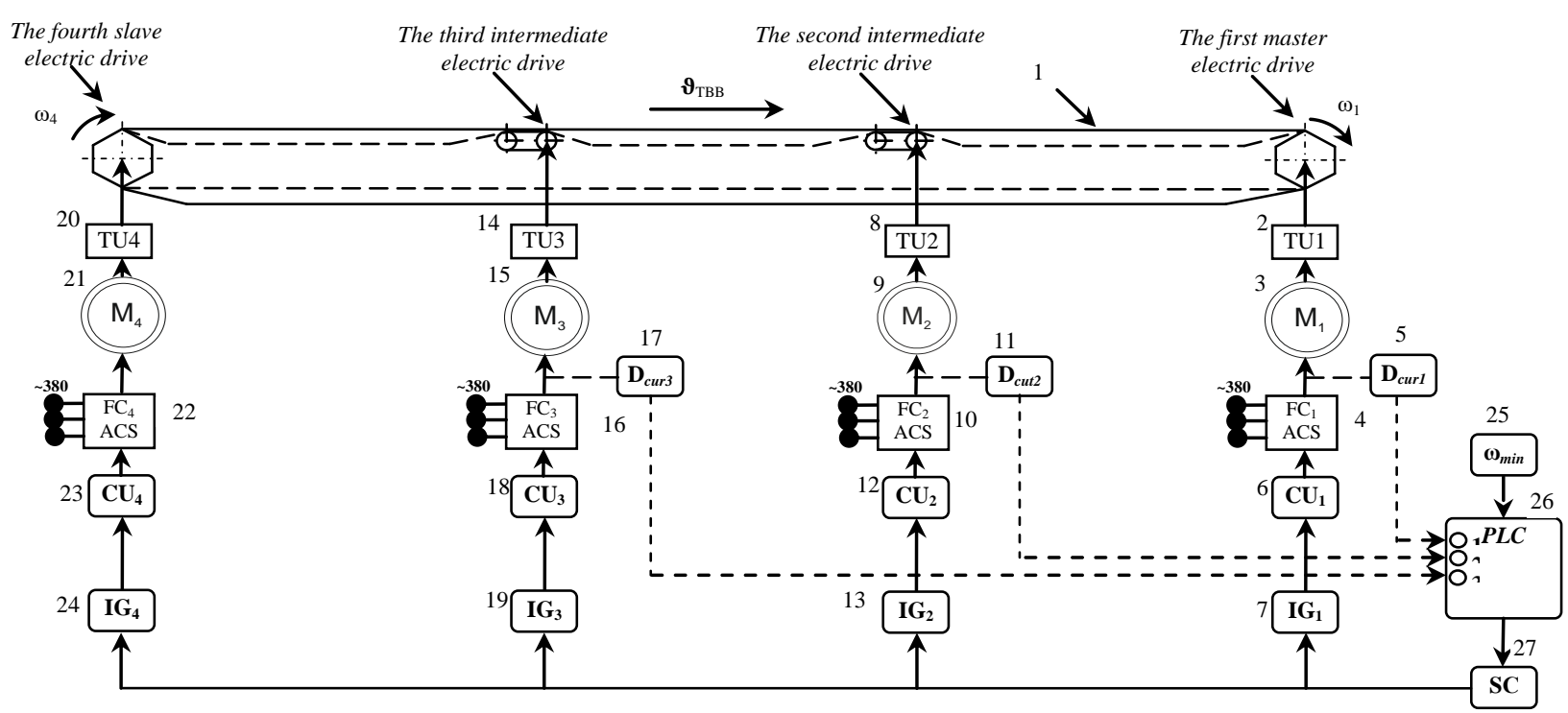

Fig.1. Block diagram of a frequency-controlled multi-motor electric drive with a smooth start system foran apron conveyor

The first master, the second slave intermediate and the third slave intermediate electric drives smoothly pull out the slack of the traction chain until the upper branch of the traction carrier is fully drawn, which will be evidenced by the actuation of all the three current sensors.

The mathematical description of the initial moment of starting a multi-drive (four-drive) an apron conveyor is represented by the following equations:

where

$$
\begin{aligned}
& J_{1} \frac{d \omega_{1}}{d t}=M_{A M 1}-M_{c 1} \\
& J_{2} \frac{d \omega_{2}}{d t}=M_{A M 2}-M_{c 2} \\
& J_{3} \frac{d \omega_{3}}{d t}=M_{A M 3}-M_{c 3}
\end{aligned}
$$

$J_{1}$ is the moment of inertia of the first electric drive;

$I_{2}$ is the moment of inertia of the second electric drive;

$J_{3}$ is the moment of inertia of the third electric drive;

$\omega_{1}, \omega_{2}$ are the angular speeds of rotation of the first and second electric drives, respectively;

$\omega_{3}$ is the angular speed of rotation of the third electric drive rotor;

$M_{A M 1}$ is the electromagnetic moment of the first master electric motor;

$M_{c 1}$ is the static moment reduced tothe first motor shaft; 
$M_{A M 2}$ is the electromagnetic moment of the second slave motor;

$M_{c 2}$ is the static moment reduced to the second motor shaft;

$M_{A M 3}$ is the electromagnetic moment tothe third slave motor;

$M_{c 3}$ is the static moment reduced to the third motor shaft.

At the initial moment of starting the 1st, the 2nd, and 3rd asynchronous electric motors, the working body (chain) is drawn out, so, there is no elasticity at the moment. In this regard, the fourth electric drive is restrained, so, $\omega_{4}=0$.After full drawing the working branch of the traction-bearing body from the controller PLC through the corresponding control units, a signal is sent to accelerate all the four electric drives to the rated rotation speed. This moment of acceleration of electric drives is represented by the following system of equations:

$$
\begin{aligned}
& J_{1} \frac{d \omega_{1}}{d t}=M_{A M 1}-M_{c 1}-M_{l}-\mathrm{c}_{1} \int\left(\omega_{1}-\omega_{2}\right) d t+\mathrm{c}_{1} \int\left(\omega_{4}-\omega_{1}\right) d t, \\
& J_{2} \frac{d \omega_{2}}{d t}=M_{A M 2}-M_{c 2}-M_{l}+\mathrm{c}_{2} \int\left(\omega_{2}-\omega_{1}\right) d t+\mathrm{c}_{2} \int\left(\omega_{2}-\omega_{3}\right) d t, \\
& J_{3} \frac{d \omega_{3}}{d t}=M_{A M 3}-M_{c 3}-M_{l}+\mathrm{c}_{3} \int\left(\omega_{3}-\omega_{2}\right) d t+\mathrm{c}_{3} \int\left(\omega_{3}-\omega_{4}\right) d t, \\
& J_{4} \frac{d \omega_{4}}{d t}=M_{A M 4}-M_{c 4}+\mathrm{c}_{4} \int\left(\omega_{4}-\omega_{1}\right) d t+\mathrm{c}_{4} \int\left(\omega_{4}-\omega_{3}\right) d t
\end{aligned}
$$

where

$c_{1}, c_{2}$ are the rigidity factors of the $1^{\text {st }}$ and the $2^{\text {nd }}$ electric drives, respectively;

$c_{3}, c_{4}$ are the rigidity factors of the $3^{\text {rd }}$ and the $4^{\text {th }}$ electric drives, respectively;

$J_{4}$ is the moment of inertia of the $4^{\text {th }}$ electric drive;

$\omega_{4}$ is the angular speed of rotation of the $4^{\text {th }}$ electric drive rotor;

$M_{A M 4}$ is the electromagnetic moment of the $4^{\text {th }}$ slave motor;

$M_{c 4}$ is the static moment reduce to the $4^{\text {th }}$ drive shaft;

$M_{l}$ is the moment of resistance from the load.

The proposed block diagram of a frequency-controlled multi-motor electric drive with a smoothstarting system for apron conveyor can be implemented as follows and includes standard units.The traction-bearing body of an apron conveyor 1 is a load-bearing belt made of steel plates attached to the chain traction body, while the first transfer unit (TU1) 2, the second transfer unit (TU2) 8, the third transfer unit (TU3) 14, the fourth transfer unit (TU4) 20 are made in the form of standard helical gearboxes.

The first electric motor 3 of the first master electric drive, the second electric motor 9 of the second intermediate electric drive, the third electric motor 15 of the third intermediate electric drive and the fourth electric motor 21 of the fourth slave electric drive are asynchronous electric motors with a squirrel-cage rotor. The first current sensor 5, the second current sensor 11 and the third current sensor 17 are standard sensors that measure electric current consumed by the electric motor. The first frequency converter $\left(\mathrm{FC}_{1}+\mathrm{ACS}\right) 4$, the second frequency converter $\left(\mathrm{FC}_{2}+\mathrm{ACS}\right) 10$, the third frequency converter $\left(\mathrm{FC}_{2}+\mathrm{ACS}\right) 16$ and the fourth frequency converter $\left(\mathrm{FC}_{4}+\mathrm{ACS}\right) 22$ are standard converters that convert alternating voltage of the mains voltage into varying frequency of power supply of electric motors $3,9,15,21$, respectively. The first control unit $\left(\mathrm{CU}_{1}\right) 6$, the second control unit $\left(\mathrm{CU}_{2}\right)$ 12, the third control unit $\left(\mathrm{CU}_{3}\right)$ 18, the fourth control unit $\left(\mathrm{CU}_{4}\right) 23$ are standard control units for frequency converters. The first intensity generator $\left(\mathrm{IG}_{1}\right) 7$, the second intensity generator $\left(\mathrm{IG}_{2}\right) 13$, the third intensity generator $\left(\mathrm{IG}_{3}\right) 19$ and the fourth intensity generator $\left(\mathrm{IG}_{4}\right) 24$ are made in the form of standard intensity generators providing a smooth change in the output signal to the values corresponding to the set speed values. The block of setting the minimum speed 25 is performed in the form of a controlled voltage divider. The speed controller 27 is made in the form of a standard element that sets the speed, in this case, it accepts the task for the minimum speed at the initial moment of starting, and at full drawing of the working branch for accelerating the rotation of all the electric drives to the rated speed value. The PLC controller 26 is a programmable logic controller used to automate technological processes, energy, transport and other control systems.

\section{Results and discussion}

Based on the results of the research, an algorithm was developed for starting a four-motor electric drive of the conveyor, which can be carried out in the following order (Figure 2). 

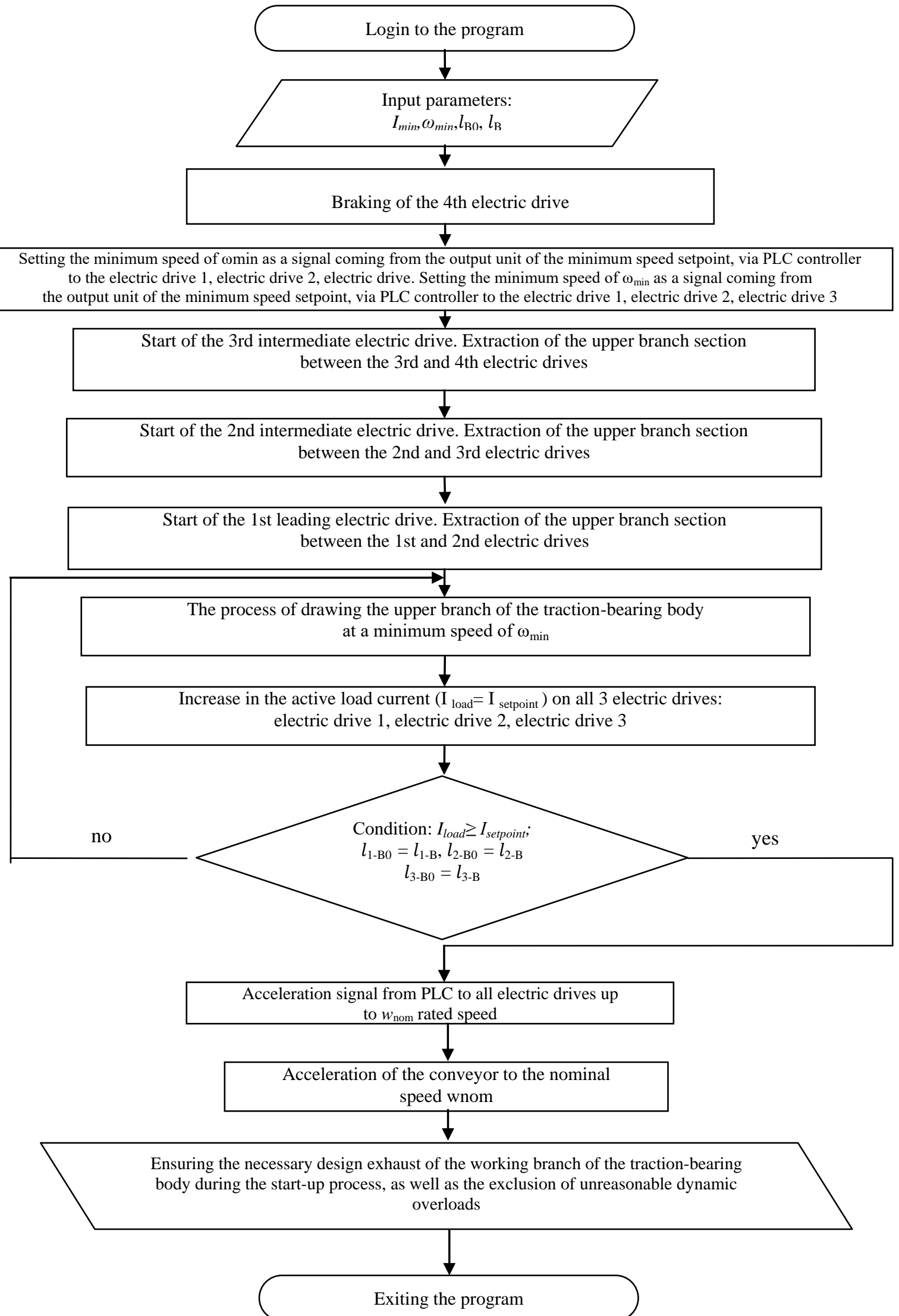

Fig.2. Block diagram of the algorithm for controlling the start of a four-motor electric drive of an apron conveyor. 
At the initial moment before starting the multi-motor electric drive of apron conveyor, the fourth slave electric drive of the conveyor is fixed by braking. Then, in the following sequence, the following are started: the third intermediate electric drive, the second intermediate electric drive, the first leading electric drive and, at the minimum speed of movement, the upper working branch of the traction-bearing body 1 is extracted, while each electric drive is the corresponding sections between the fourth and third, third and second, second and first drives. The minimum rotation speed is set by a signal coming from the output of the minimum speed set point unit 25, via the PLC controller 26, the speed setter 27 . The output signal of the speed setter 27 enters the inputs, respectively, of the first intensity setter 7 , the second intensity setter 13 , the third intensity setter 19 and provides a smooth change in speeds by setting the input of the first control unit 6 , the second control unit 12 , the third control unit 18 signal corresponding to the minimum frequency of the output voltage of the first frequency converter 4 , the second frequency converter 10 and the third frequency converter 16.Accordingly, the driving electric motor 3, the second intermediate electric motor 9, the third intermediate electric motor 15 through the first transfer device 2, the second transfer device 8 and the third transfer device 14 begin to pull the working branch of the traction-bearing body 1 .

The signal of full extraction of the working branch of the traction-bearing body 1 will be an increase in the active current consumed by the load of electric motors 3, 9, 15. Further, from the first current sensor 5, the second current sensor 11, the third current sensor 17, the signals are sent to the PLC controller 26 simultaneously or in different order depending on the amount of sagging of the working branch sections until the conveyor is started. In this case, the condition for full extraction of the working branch of the tractionbearing body 1 is the receipt of signals from all current sensors 5, 11, 17 (about an increase in the active component of the load current of the first, second and third electric motors 3,9,15) to the PLC controller 26. After that, the algorithm (recorded in the PLC controller 26) is triggered to generate an acceleration signal with the same value up to the nominal rotation speed of the interconnected multi-motor electric drive.This signal from the PLC controller 26 output goes to the speed setter 27, and then through the corresponding setters $(7,13,19,24)$, control units $(6,12,18,23)$, frequency converters $(4,10,16,22)$, asynchronous electric motors $(3,9,15,21)$,transfer devices $(2,8,14,20)$ and through the corresponding sprockets, the tractionbearing body of apron conveyor is accelerated to the nominal value.

Verification of the operation of the developed algorithm for starting a four-motor electric drive of the conveyor was previously implemented in the computer environment of the FRCONFIGURATOR2 program at the benches of the Mitsubishi Electric with a frequency converter of the FR-A800 series of the Automation of Production Processes Department of Karaganda Technical University. The frequency of the electric motor was controlled through external control devices: toggle switches STR, RH, RM, RL by switching which the starting signal was supplied. The graphs of changing the values of the output electrical characteristics of conveyor electric motors (frequency, current and voltage) obtained by the results of bench tests in on-line mode through the function "Function - Trend monitor" are shown in Figure 3.

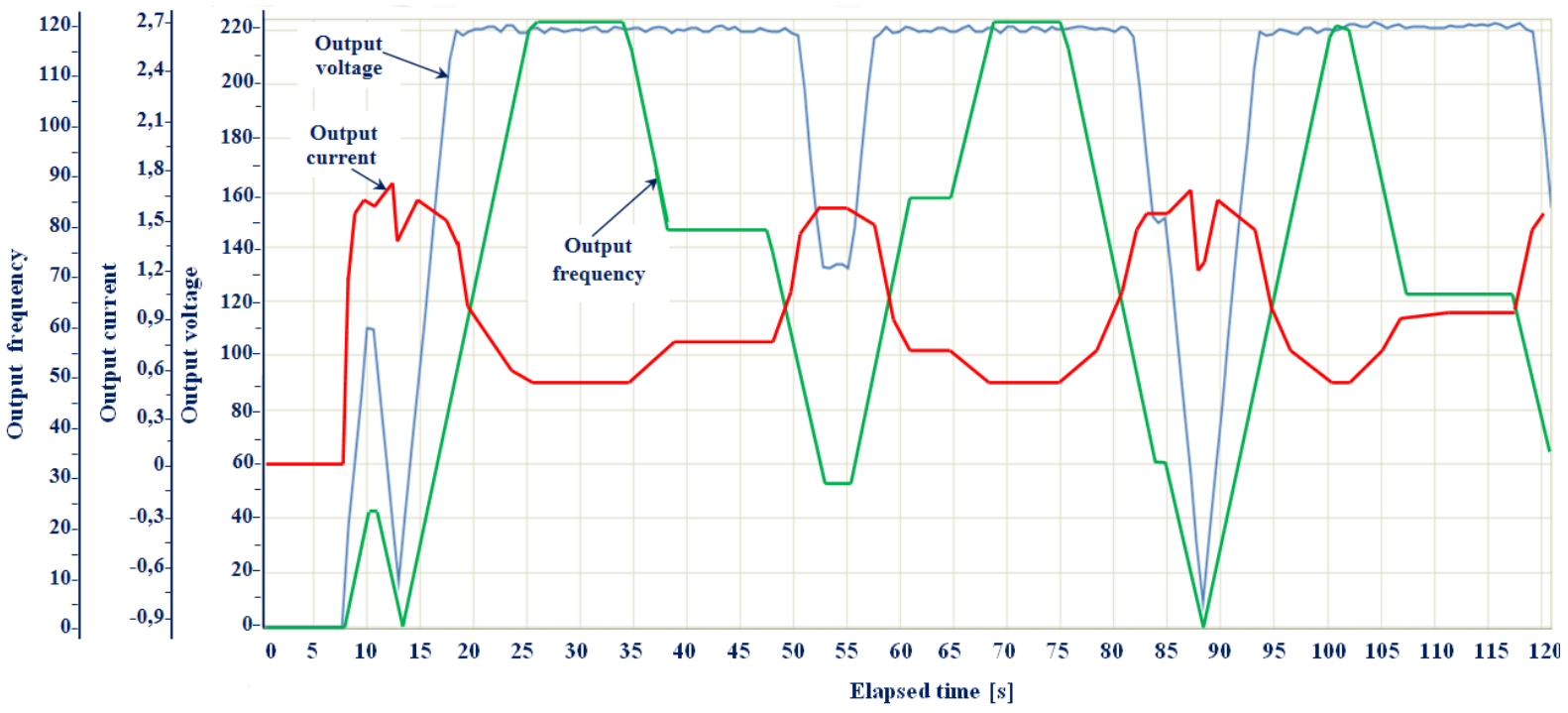

Fig.3. Dynamics of changing the characteristics of electric motors of a four-drive apron conveyor in the starting mode of operation 
The analysis of the obtained graphs shows that at the initial moment of starting the conveyor, up to about 13 seconds from start-up, the main electrical characteristics of the drive (current, voltage, frequency) change the same way. Then, as the motor armature speed increases, the output voltage value increases, and the amount of consumed current changes inversely proportional to the voltage and frequency. As already noted, in the developed block diagram of the algorithm for controlling the start of a four-motor electric drive of an apron conveyor, the signals of smooth pulling of the working branch of the traction-bearing body will be periods of the stepwise increasing of the active load current of the first, second and third electric motors, as shown by the dynamics of changes in the characteristics of electric motors obtained in laboratory conditions when starting a multi-drive conveyor.

\section{Conclusion}

Thus, based on the results of comprehensive studies, the authors propose a method of controlling the starting mode of operation of an interconnected frequency-controlled four-motor electric conveyor drive based on measuring load currents and isolating their active components, which, in comparison with the existing analogues, makes it possible to achieve the necessary calculated extraction of the working branch of the traction-bearing belt during the conveyor start, which, in the authors' opinion will eliminate unreasonable static and dynamic overloads in the traction body.

The field observations of the starting modes of the KM PP 2-10-60 apron feeder operation with a Mitsubishi Electric E-700 frequency converter used to supply coal to the concentrator in the conditions of the Molodezhnaya coal mine of the Kazakhmys Coal LLP, in accordance with the conclusions of production specialists, confirmed the identity of the data obtained in laboratory conditions by computer modeling in the FRCONFIGURATOR2 environment. Accordingly, the estimated increasing of the economic efficiency from the operation of a multi-driveapron conveyor, taking into account the smooth start of its traction-bearing body, is determined by the following:

- increasing the service life of the conveyor by 1.2-1.3 times due to decreasing the dynamic and static loads on the working body of the conveyor and increasing its fatigue life;

- reducing the costs for maintenance and overhaul of the working body of the conveyor by $27-28 \%$.

As itwas noted, the developed method makes it possible to implement the necessary mode of starting the conveyor without additional equipping it with a tensioner.

\section{Acknowledgments}

The authors are appreciated and express deep gratitude to Doctor of technical sciences, Professor Breido I.V. who died suddenly in July 2021 , for consultations and valuable advice in preparing this article.

\section{REFERENCES}

1 Saginov A.S., Daniyarov A.N., Akashev Z.T. Fundamentals of design and calculation of career apron conveyors. Alma-Ata: Nauka,1987, 328 p. [in Russian]

2 Verma M., et al. Medium Voltage Adjustable Speed Drives: Power Factor and Motor Control-A Beautiful Combination. Conference Proceedings - IEEE-IAS/PCA Cement Industry Technical Conference, 2019, pp. 14-16.

3 Pajchrowski T. Comparison of control structures for direct drive with PMSM motor with variable inertia and load torque. Przeglad Elektrotechniczny. 2018, 94(5), pp. 133-138.

4 WojcikA., Pajchrowski T. Application of iterative learning control for ripple torque compensation in PMSM drive. Archives of Electrical Engineeringthis link is disabled, 2019, 68(2), pp. 309-324.

5 Štatkić, S., Jeftenić, I.B., Bebić, M.Z., et al. Reliability assessment of the single motor drive of the belt conveyor on Drmno open-pit mine. International Journal of Electrical Power and Energy Systems. 2019, 113, pp. 393402 .

6 Windmann S., Niggemann O., Stichweh H. Computation of energy efficient driving speeds in conveying systems. At-Automatisierungstechnik, 2018, 66 (4), pp. 308-319.

7 Świder J., Herbuś K., Szewerda K. Control of Selected Operational Parameters of the Scraper Conveyor to Improve Its Working Conditions. Advances in Intelligent Systems and Computing. 2019, No. 934, pp. 395-405.

8 Semykina I.Y., Tarnetskaya A.V. Control of energy efficient belt conveyor gearless drum-motor. EAI Endorsed Transactions on Energy Web. 2019, 19(22), pp 144-146.

9 Pajchrowski T., Wójcik A. Analysis of influence of linear regulators' structure on level of speed unevenness of PMSM direct drive. PMSM. Przeglad Elektrotechniczny. 2020, No. 96(7), pp. 59-67. 
10 Kashirskikh V., et al. On the Issue of Increasing Reliability of Electric Mining Machinery. E3S Web of the International Innovative Mining Symposium, IIMS. 2020, Vol. 174, Article No. 03024, $11 \mathrm{p}$. doi:10.1051/e3sconf/202017403024.

11 Semykina I.Y., Tarnetskaya A.V. Control of energy efficient belt conveyor gearless drum-motor. EAI Endorsed Transactions on Energy Web. 2019, Vol. 19, Issue 22, 6p. doi:10.4108/eai.13-7-2018.156435.

12 Eshchin E.K. Model of asynchronous motor in power supply system. Russian Electrical Engineering. 2002, Vol. 73, Issue 1, pp. 53-58.

13 Eshchin E.K. Reduction to risk of operation of systems of electro supply of coal mining equipment. Ugol'. 2005, Issue 9, pp. 39 - 42. [in Russian]

14 Eshchin E.K. Scraper face conveyors dynamic load control. Journal of Mining Institute. 2019, Vol. 239, pp. 570-575.

15 Daniyarov A.N., Akashev Z.T., Rozhkov A.V., Kuchin V.N. A method of tensioning a traction element of a multi-drive conveyor. Patent of USSR, No. 1312025, Publ. 05.23.1987, Bul. 19, 5 p. [in Russian]

16 Breido I.V., Kelisbekov A.K. Method for smooth start-up of a multi-motor electric drive of an apron conveyor. Utility model patent of the Republic of Kazakhstan.No. 3982, Publ. 05.03.2019, 4 p. [in Russian]

17 Breido I.V., Daniyarov N.A., Kelisbekov A.K. Method of controlling the start of a multi-motor electric drive of an apron conveyor.Utility model patent of the Republic of Kazakhstan. No. 5122. Publ.07.03.2020, 5 p. [in Russian] 